\title{
Eficiência ótima do equipamento tipo jato cavitante com múltiplos jatos
}

\author{
Thais V. Omido (IC), José G. Dalfré Filho (PQ), Ana I. B. Genovez (PQ), Maiara P. Assis (PG).
}

\section{Resumo}

Diante da situação de escassez hídrica, torna-se imprescindível o desenvolvimento de tecnologias alternativas de tratamento de água. Dentre as técnicas alternativas exploradas, encontra-se o uso do equipamento tipo jato cavitante, que gera um jato cavitante de alta velocidade. A cavitação, usualmente considerada prejudicial aos sistemas hidráulicos, é empregada neste projeto para o útil objetivo de inativar bactérias presentes na água. Foram feitos testes hidráulicos, físico-químicos e microbiológicos com o equipamento tipo jato cavitante com múltiplos jatos, empregando a bactéria não patogênica Escherichia coli, determinando as eficiências de inativação para diferentes bocais que geram os jatos cavitantes.

Palavras Chave: cavitação, jato cavitante, inativação de bactérias.

\section{Introdução}

A cavitação é um processo de vaporização do líquido, quando a pressão deste cai até o valor da pressão de vapor, a uma dada temperatura. Uma das formas de gerar a cavitação é com o equipamento tipo jato cavitante. Este equipamento pode ser otimizado alterando-se a geometria dos bocais e das pressões que geram o jato cavitante de alta velocidade, garantindo maior eficiência de inativação de bactérias presentes em água, com um consumo menor de energia e melhorando a qualidade da água. $\mathrm{O}$ equipamento tipo jato cavitante é apresentado na Figura 1.

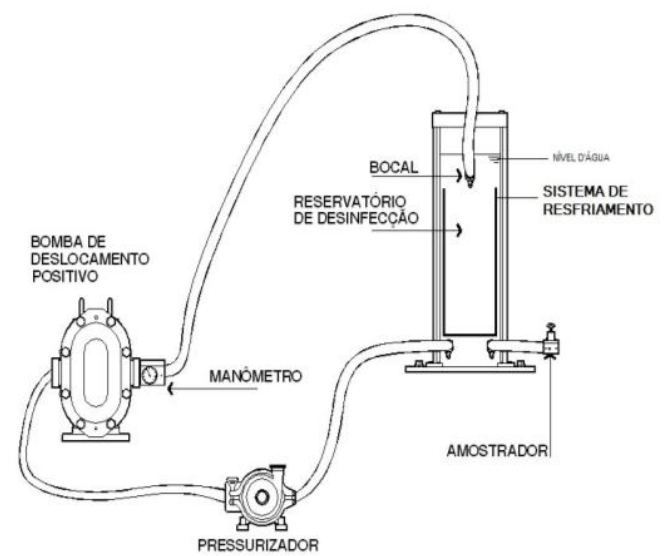

Figura 1. Equipamento tipo jato cavitante ${ }^{1}$.

O objetivo do projeto foi encontrar um ponto de eficiência ótima do equipamento tipo jato cavitante com múltiplos jatos para a inativação de bactérias.

\section{Resultados e Discussão}

Os ensaios envolveram testes hidráulicos para verificar as condições do equipamento para ensaio, testes físico-químicos para verificar se os resíduos se enquadram nos padrões da legislação para lançamento de efluentes e testes microbiológicos, empregando o sistema Colilert ${ }^{\circledR}$ para avaliação da inativação de Escherichia coli.

De acordo com a Figura 2, verifica-se que a configuração plana com 8 bocais de $0,5 \mathrm{~mm}$ a $20 \mathrm{MPa}$ é a mais eficiente para inativação. Para pressões mais elevadas, as configurações com mais bocais apresentam maior porcentagem de inativação, enquanto o bocal único se mostra mais eficiente a pressões menores.

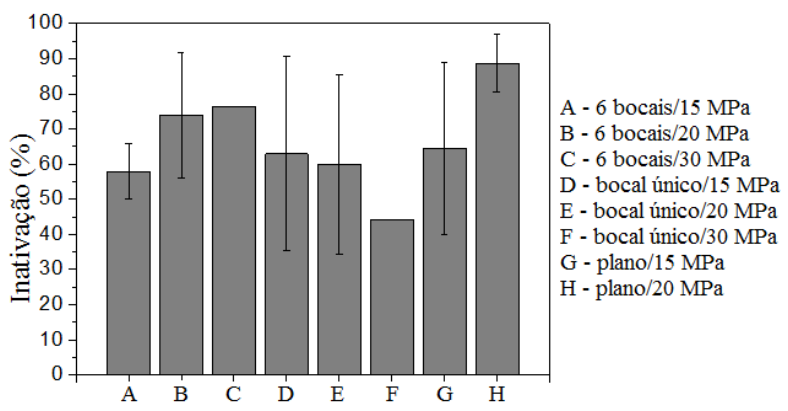

Figura 2. Inativação de Escherichia coli para diferentes bocais e pressões de testes.

\section{Conclusões}

O equipamento tipo jato cavitante pode ser empregado para inativação de bactérias e a melhor configuração com relação ao consumo de energia encontrado foi a plana a $20 \mathrm{MPa}$.

\section{Agradecimentos}

Aos Profs. Dr. José Gilberto Dalfré Filho e Dra. Ana Inés Borri Genovez, à MSc. Maiara Pereira Assis, aos técnicos do LHMF e do LABSAN da $\mathrm{FEC}$, ao $\mathrm{CNPq}$ e à FAPESP pelo processo 2012/09843-8.

OMIDO, T.V.; DALFRÉ FILHO, J.G.; GENOVEZ, A.I.B. Relatório do projeto de pesquisa "Ensaios de inativação com o equipamento tipo jato cavitante com múltiplos jatos”. Relatório de pesquisa de Iniciação Científica PIBIC 2013-2014. 